J. Pijar MIPA, Vol. V No.2, September : 57 - 61

ISSN 1907-1744

\title{
SINTESIS FEROMON 6-METIL-2-HEPTEN-4-OL DARI KROTONALDEHID MELALUI PEMBENTUKAN REAGEN GRIGNARD ISOBUTILMAGNESIUM BROMIDA
}

\author{
Putu Indrayani ${ }^{*}$, Aliefman Hakim ${ }^{2}$ \\ ${ }^{1}$ SMA Negeri 2 Sumbawa Besar, Jl. Garuda No. 102 Sumbawa Besar, Indonesia. \\ ${ }^{2}$ Program Studi Pendidikan Kimia PMIPA FKIP Universitas Mataram \\ Jl. Majapahit 62 Mataram 83125
}

\begin{abstract}
Abstrak : Sintesis 6-metil-2-hepten-4-ol diawali dengan pembentukan reagen Grignard isobutilmagnesium bromida pada $40^{\circ} \mathrm{C}$ selama 1 jam, dilanjutkan dengan pembentukan garam alkoksi magnesium bromida pada $0^{\circ} \mathrm{C}$. Hidrolisis terhadap garam alkoksi magnesium bromida dengan larutan $\mathrm{NH}_{4} \mathrm{Cl}$ jenuh menghasilkan 6-metil-2-hepten4-ol. Hasil sintesis kemudian diuji sifat fisiko-kimianya meliputi berat jenis, indeks bias serta identifikasi dengan Spektrofotometer Inframerah (IR), Kromatografi Gas (GC) dan Kromatografi Gas-Spektrometer Massa (GC-MS). Hasil sintesis menghasilkan cairan beraroma manis segar, berwarna kekuningan, berat jenis $0,815^{29} \mathrm{~g} / \mathrm{mL}$, indeks bias $1,408^{30}$, kemurnian $66,07 \%$ dan hasil 46,31\%. Karakter IR senyawa hasil sintesis menunjukkan vibrasi ulur O-H alkohol pada $3361 \mathrm{~cm}^{-1}$, vibrasi ulur C-OH pada $1049,2 \mathrm{~cm}^{-1}$, vibrasi ulur $\mathrm{C}=\mathrm{C}$ pada $1676 \mathrm{~cm}^{-1}$ dan serapan 2956,7 dan $2920 \mathrm{~cm}^{-1}$ untuk vibrasi ulur $\mathrm{C}-\mathrm{H}$ dalam $\mathrm{CH}_{3}$ dan spektra massa dengan $\mathrm{m} / \mathrm{e} 128$ yang dicapai pada waktu retensi 6,284 menit. Data-data tersebut mendukung bahwa senyawa hasil sintesis adalah 6-metil-2-hepten-4-ol.
\end{abstract}

Kata kunci : Sintesis, reaksi Grignard dan 6-metil-2-hepten-4-ol

\section{SYNTHESIS OF 6-METHYL-2-HEPTEN-4-OL FROM CROTONALDEHIDE THROUGH FORMATION OF GRIGNARD REAGENT ISOBUTYLMAGNESIUM BROMIDE}

\begin{abstract}
Synthesis of 6-methyl-2-hepten-4-ol was generated with formation of Grignard reagent Isobutylmagnesium bromide carried out at $40^{\circ} \mathrm{C}$ for one hour, then formation of alcoxide salt magnesium bromide carried out at $0^{\circ} \mathrm{C}$. Alcoxide salt magnesium bromide were hydrolyzed by saturated $\mathrm{NH}_{4} \mathrm{Cl}$ solution producing 6methyl-2-hepten-4-ol. Results were examined physically and chemically including density, refraction index, pure percentage and yield percentage were $0,815^{29} \mathrm{~g} / \mathrm{mL}, 1,408^{30}, 66,07 \%$ and $46,31 \%$ respectively. The IR characters showed stretching vibration of O-H group at $3361 \mathrm{~cm}^{-1}$, stretching vibration C-OH group at $1049,2 \mathrm{~cm}^{-1}$, stretching vibration $\mathrm{C}=\mathrm{C}$ group at $1676 \mathrm{~cm}^{-1}$ and absorption of $\mathrm{C}-\mathrm{H}$ in $\mathrm{CH}_{3} 2956,7$ and $2920 \mathrm{~cm}^{-1}$. Identification using GC-MS resulted spectra $\mathrm{m} / \mathrm{e} 128$ at time retention 6,284 minutes. The proven data indicated that the resulted compound was 6methyl-2-hepten-4-ol.
\end{abstract}

Keywords : synthesis, Grignard reaction and 6-methyl-2-hepten-4-ol

\section{PENDAHULUAN}

Jawa timur merupakan salah satu daerah yang berpotensi besar sebagai penghasil buah kelapa. Namun pengembangan potensi daerah ini terhambat karean serangan hama Rhynchoporus spp, yang menyebabkan tanaman kelapa banyak yang mati. Perkebunan kelapa yang rusak akibat serangan hama mencapai 110 ha setiap kali penyerangannya, umumnya berada didaerah pantura [5]. Pengendalian hama menggunakan pestisida menimbulkan efek samping yang merugikan, antara lain dapat membunuh mahkluk lain bukan sasaran, hama dapat mengalami kekebalan dan sulit terdegradasi dalam tanah sehingga dapat menimbulkan pencemaran tanah. Salah satu alternatif teknologi yang dapat dipilih adalah Pengendalian Hama Terpadu (PHT) dengan melibatkan feromon [3].

Feromon agregat yang disekresi oleh Rhynchoporus schach yaitu 6-metil-2-hepten-4-ol tergolong alkohol sekunder [1]. Sintesis alkohol sekunder telah banyak dilakukan. Alkohol sekunder 4-metil-3heptanol disintesis dengan satu tahap reaksi menggunakan reaksi Grignard [6], Zarbin mensintesis 5-metil-2-hepten- 4-on disintesis dengan 4 tahap reaksi, jika direduksi akan menjadi alkohol sekundernya [7]. Penetapan bahan dasar dalam sintesis tersebut dilakukan dengan analisis retrosintesis terhadap molekul target. Dengan cara ini jalur sintesis 4-metil-3-heptanol dapat dirancang menggunakan bahan dasar propanal dan 2-metil-1-butanol [6], dengan cara yang sama Zarbin mensintesis 5-metil-2-hepten-4on menggunakan bahan dasar 2-metil-1-butanol dan keton yang diperoleh direduksi untuk mendapatkan alkohol sekundernya [7].

Berdasarkan analisis tersebut diperoleh jalur sistesis 6-metil-2-hepten-4-ol dengan reaksi Grignard dapat dirancang menggunakan bahan dasar krotonaldehid (2-butenal) dan reagen Grignard isobutil magnesium bromida dengan satu tahap reaksi. Beberapa pertimbangan dalam menetapkan tahapan sintesis antara lain tahapan reaksi yang pendek, bahan dasar yang murah dan tersedia serta rendemen produk yang tinggi [6]. Berdasarkan pertimbangan tersebut maka dipilih sintesis alkohol sekunder 6-metil-2-hepten-4-ol dengan reaksi Grignard, menggunakan bahan dasar krotonaldehid dan reagen 
Grignard isobutil magnesium bromida hanya denga satu tahap reaksi.

\section{METODE PENELITIAN}

\subsection{Bahan-bahan yang digunakan}

Bahan-bahan yang digunakan pada penelitian berderajat p.a (kecuali bila disebutkan lain) antara lain logam magnesium, Kristal iodin, ammonium klorida, magnesium sulfat hepta hidrat, natrium hidrogen bikarbonat, gas helium dan gas nitrogen $70 \%$. Bahan bahan yang dikeringkan dengan magnesium sulfat anhidrat yaitu dietil eter, isobutil bromida dan krotonaldehid.

\subsection{Alat-alat yang digunakan}

Seperangkat alat gelas, thermometer, seperangkat alat refluks, stirrer magnet, pompa air, rotary evaporator vaccum, identifikasi dengan spektrofotometer IR menggunakan tipe Shimadzu FT-IR-8210 PC, dan identifikasi dengan GC-MS menggunakan tipe Shimadzu QP-5000, kolom CP SIL 5 CB; ID 0,25 mm; Film : 0,5 um, suhu detektor $280^{\circ} \mathrm{C}$, suhu injektor $280^{\circ} \mathrm{C}$, suhu oven $70-200^{\circ} \mathrm{C}$ dengan kenaikan temperatur $10^{\circ} \mathrm{C} /$ menit, gas pembawa $\mathrm{He}$, sedangkan analisa kuantitatif menggunakan Kromatografi gas (GC) tipe Hewlett Pacard 5890 series II, kolom HP 5; ID 0,32 mm; Film 0,50 um, suhu detektor $280^{\circ} \mathrm{C}$, suhu injektor $270^{\circ} \mathrm{C}$, suhu oven $120-250^{\circ} \mathrm{C}$ dengan kenaikan temperatur $10^{\circ} \mathrm{C} /$ menit, gas pembawa $\mathrm{He}$.

\subsection{Cara kerja}

\subsubsection{Sintesis 6-metil-2-hepten-4-ol}

Kedalam labu alas bulat leher tiga $250 \mathrm{~mL}$ yang dilengkapi dengan kondensor dan thermometer dimasukkan serpihan logam magnesium 1,46 g (0,06 mol) ditambah $15 \mathrm{~mL}$ eter kering dan 0,05 g iodine. Disiapkan larutan isobutil bromida kering $6,5 \mathrm{~mL}(0,06 \mathrm{~mol})$ ditambah $15 \mathrm{~mL}$ eter kering dalam corong pisah. Melalui corong pisah ditambahkan larutan isobutil bromida $( \pm 5$ $\mathrm{mL}$ ) ditambahkan kedalam labu, dibiarkan beberapa saat sampai terjadi reaksi, yang ditandai dengan timbulnya gelembung-gelembung gas. Saat mulai terjadi reaksi dilakukan pengadukan dan ditambah $10 \mathrm{~mL}$ eter, bila reaksi terlalu hebat labu didinginkan dalam air dingin (es). Setelah reaksi reda, ditambahkan sisa larutan isobutil bromida tetes demi tetes sampai habis. Campuran cairan berwarna abu-abu yang terbentuk diaduk dan direfluks selama 1 jam pada suhu $40^{\circ} \mathrm{C}$. Labu didinginkan sampai temperatur $0^{\circ} \mathrm{C}$. setelah itu reagen Grignard yang terbentuk ditambahkan larutan krotonaldehid kering 4,9 mL (0,06 mol) dalam $15 \mathrm{~mL}$ eter kering kedalam labu tetes sambik diaduk. Labu didinginkan sampai mencapai suhu kamar. Campuran dituang dalam gelas piala $500 \mathrm{~mL}$ yang berisi campuran air es dan $70 \mathrm{~mL}$ larautan ammonium klorida jenuh sambil diaduk. Campuran dimasukkan dalam corong pisah $250 \mathrm{~mL}$ sampai terbentuk dua lapisan. Kemudian lapisan organik dipisahkan, lapisan air diekstrak dengan $3 \times 15 \mathrm{~mL}$ eter. Lapisan organik digabungkan dan dicuci dengan $20 \mathrm{~mL}$ larutan natrium hidrogen karbonat jenuh, lapisan organik dipisahkan dan dicuci dengan $20 \mathrm{~mL}$ aquades, dipisahkan. Lapisan organik dikeringkan dengan garam magnesium sulfat anhidrat. Eter diuapkan dengan menggunakan evaporator vakum kemudian dipekatkan dengan menggunakan gas $\mathrm{N}_{2}$ untuk mendapatkan 6-metil2-hepten-4-ol.

\subsubsection{Identifikasi senyawa 6-metil-2-hepten-4-ol hasil sintesis}

Senyawa hasil sintesis kemudian diidentifikasi strukturnya menggunakan spektrofotometer IR dan GCMS sedangkan analisa kuantitatif dengan GC.

\section{HASIL DAN PEMBAHASAN 3.1 Sintesis 6-metil-2-hepten-4-ol}

Proses sintesis 6-metil-2-hepten-4-ol diawali dengan pembentukan reagen Grignard isobutil magnesium bromide. Kondisi pembentukan reagen Grignard ini harus bebas air, karena reagen Grignard merupakan basa yang sangat kuat dan akan bereaksi dengan air [2]. Reaksi ini bersifat eksotermis karena merupakan reaksi radikal bebas antara logam $\mathrm{Mg}$ dengan isobutil bromida. Berlangsungnya reaksi ditandai dengan hilangnya warna coklat dari iodin, sedangkan pembentukan reagen Grignard ditandai dengan berubahnya warna larutan menjadi warna abu-abu. Reagen Grignard yang telah terbentuk dapat menghalangi kontak logam Mg dengan isobutil bromida yang ditambahkan. Oleh karena itu untuk mereaksikan reaktan yang belum bereaksi maka diperlukan penabahan energi yang dilakukan dengan refluks pada $40^{\circ} \mathrm{C}$ selama 1 jam. Reaksi pembentukan reagen Grignard digambarkan sebagai berikut:

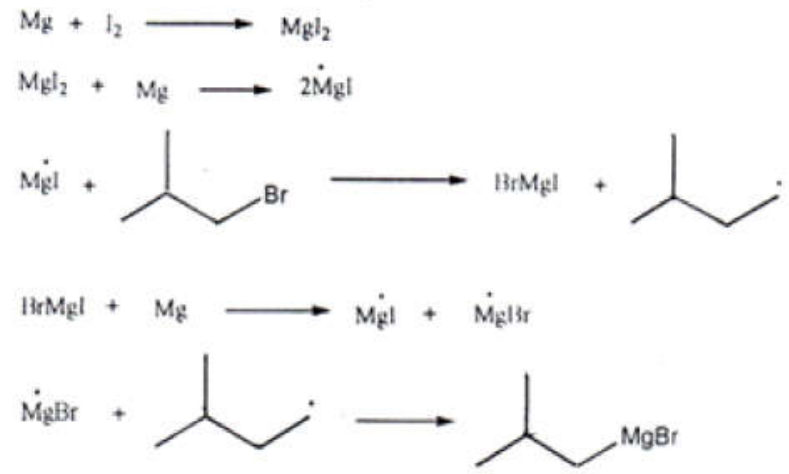

Gambar I. Reaksi pembentukan reagen Grignard

Pemakaian reagen Grignard dalam berbagai sintesis dilakukan secara in situ, sehingga penambahan aldehid dilakukan langsung setelah reagen Grignard terbentuk. Oleh karena reaksi reagen Grignard dengan aldehid juga eksotermis maka dalam proses pembentukan garam ini dilakukan penurunan suhu hingga $0^{\circ} \mathrm{C}$. terjadinya endapan putih pada waktu penambahan krotonaldehid menunjukkan telah terbentuknya garam alkoksi magnesium bromida [4]. Reaksi pembentukan garam alkoksi magnesium bromide digambarkan sebagai berikut:

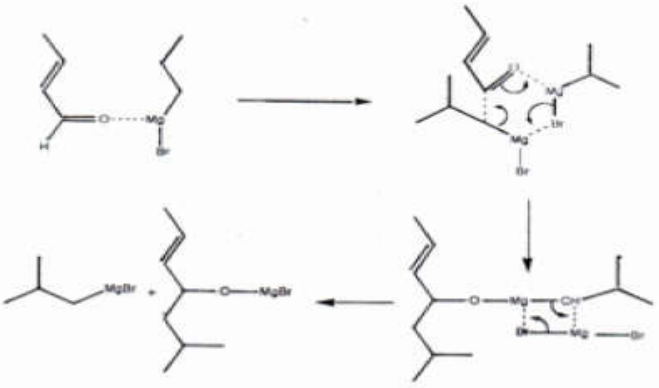

Gambar II. Reaksi pembentukan garam alkoksi magnesium bromida 
Alkohol 6-metil-2-hepten-4-ol diperoleh dengan menghidrolisis garamnya. Hidrolisis dilakukan dengan asam lemah yang berasal dari garam $\mathrm{NH}_{4} \mathrm{Cl}$ yang bertujuan agar ikatan rangkap $\mathrm{C}=\mathrm{C}$ tidak mengalami protonasi. Reaksi hidrolisis garam digambarkan sebagai berikut:

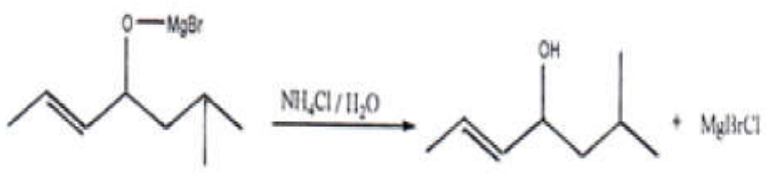

Gambar III. Reaksi hidrolisis garam

Senyawa hasil sintesis 6-metil-2-hepten-4-ol yang dihasilkan memberi kesan aroma yang manis segar dengan berat jenis $0,815^{29} \mathrm{~g} / \mathrm{mL}$ dan indeks bias $1,408^{30}$.

\subsection{Identifikasi senyawa hasil sintesis \\ 6-metil-2-hepten-4-ol}

\subsubsection{Identifikasi dengan spektrofotometer Inframerah (IR)}

Hasil pengukuran spektrum senyawa hasil sintesis 6-metil-2-hepten-4-ol diperoleh pita serapan seperti ditunjukkan dalam gambar berikut :

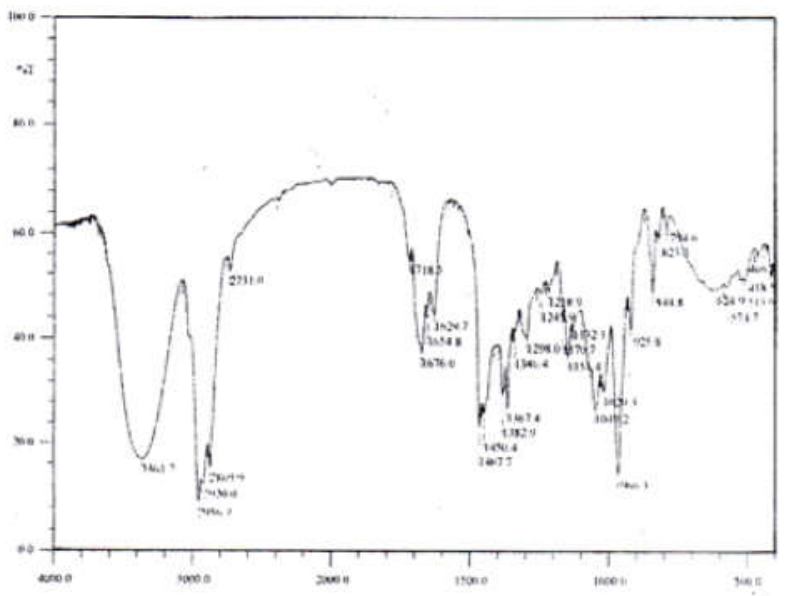

Gambar IV. Spektrum senyawa hasil sintesis 6-metil2-hepten-4-ol dengan Spektrofotometer IR

Sesuai gambar tersebut nampak bahwa senyawa 6-metil-2-hepten-4-ol telah terbentuk, hal ini dicirikan dengan munculnya pita serapan tajam dan lebar pada $3361,7 \mathrm{~cm}^{-1}$ yang menunjukkan vibrasi ulur ikatan $\mathrm{O}-\mathrm{H}$ alkohol, serta pita serapan pada 1049,2 $\mathrm{cm}^{-1}$ yang merupakan vibrasi ulur $\mathrm{C}-\mathrm{OH}$ alkohol. Adanya pita serapan pada $1676 \mathrm{~cm}^{-1}$ menunjukkan vibrasi ulur $\mathrm{C}=\mathrm{C}$, pita serapan pada $966,3 \mathrm{~cm}^{-1}$ merupakan vibrasi tekuk C$\mathrm{H}$ pada gugus vinil. Selain itu muncul pita serapan tajam pada $2956,7 \mathrm{~cm}^{-1}$ dan $2920 \mathrm{~cm}^{-1}$ yang menunjukkan vibrasi ulur C-H dalam $\mathrm{CH}_{3}$, serta pita serapan pada $1467,7 \mathrm{~cm}^{-1}$ dan $1450,4 \mathrm{~cm}^{-1}$ merupakan vibrasi tekuk $\mathrm{C}-\mathrm{H}$ dari $\mathrm{CH}_{2}$ dan serapan pada $1367,4 \mathrm{~cm}^{-1}$ dan $1382,9 \mathrm{~cm}^{-1}$ yang nerupakan vibrasi tekuk dari $\mathrm{CH}_{3}$.

\subsubsection{Identifikasi dengan spektrofotometer massa}

Berdasarkan Total Ionic Kromatogram (TIC) diketahui bahwa puncak yang diduga sebagai senyawa 6-metil-2hepten-4-ol berada pada puncak dengan $t_{R} 6,284$ menit yang pola fragmentasinya sebagaimana disajikan dalam gambar berikut:

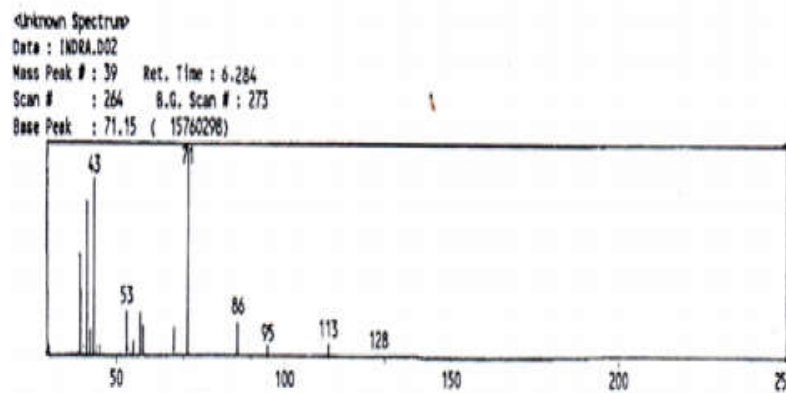

Gambar V. Spektra massa senyawa dengan $t_{R} 6,284$ menit

Puncak lemah dengan m/e 128 merupakan puncak ion molekul yang kehilangan satu elektron membentuk radikal kation. Pemecahan $\mathrm{C}-\mathrm{C}$ yang bersebelahan dengan atom oksigen (pemecahan á) yang merupakan salah satu ciri khas fragmentasi alkohol yang menghasilkan puncak dasar dengan $\mathrm{m} / \mathrm{e} 71$ serta diikuti dengan pelepasan air membentuk ion fragmen $\mathrm{m} / \mathrm{e} 53$. Pola fragmentasinya digambarkan sebagai berikut:

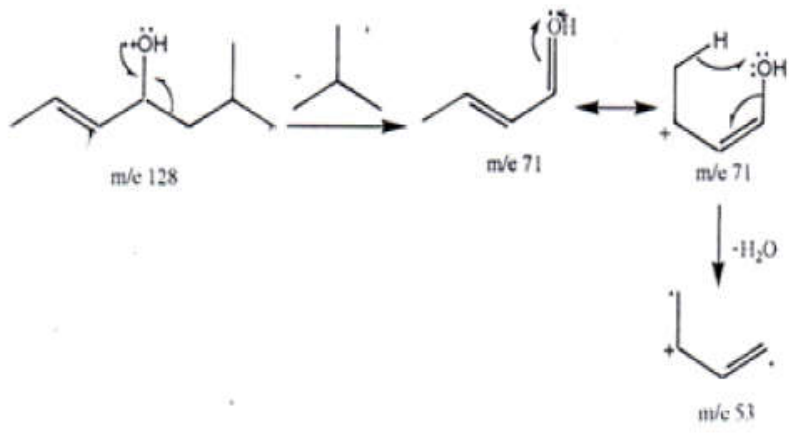

Gambar VI. Pola fragmentasi 6-metil-2-hepten-4-ol, pemecahan $\alpha$

Alkohol yang mengandung gugus metil bercabang sering menunjukkan puncak M-33 karena hilangnya air dan metil. Pada 6-metil-2-hepten-4-ol terjadi membentuk ion fragmen $\mathrm{m} / \mathrm{e} 95$ yang dilanjutkan dengan pelepasan propena membentuk ion fragmen $\mathrm{m} / \mathrm{e} 41$. Pola fragmentasinya digambarkan sebagai berikut:

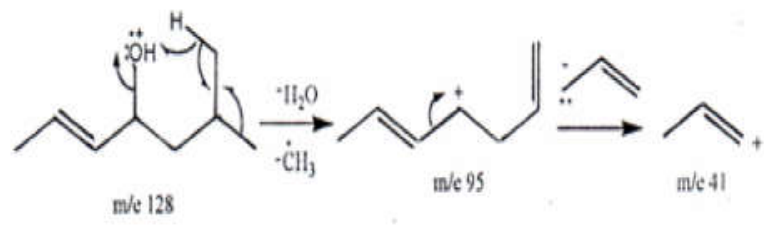

Gambar VII. Pola fragmentasi 6-metil-2-hepten-4-ol, pelepasan $\mathrm{H}_{2} \mathrm{O}$ dan $\mathrm{CH}_{3}$

Puncak dengan m/e 69 dan m/e 57 merupakan puncak ion yang terbentuk setelah 6-metil-2-hepten-4-ol mengalami dehidrasi. Namun puncak M-18 berumur pendek yang menyebabkan tidak munculnya puncak $\mathrm{m} / \mathrm{e}$ 110. Pola fragmentasinya digambarkan sebagai berikut: 


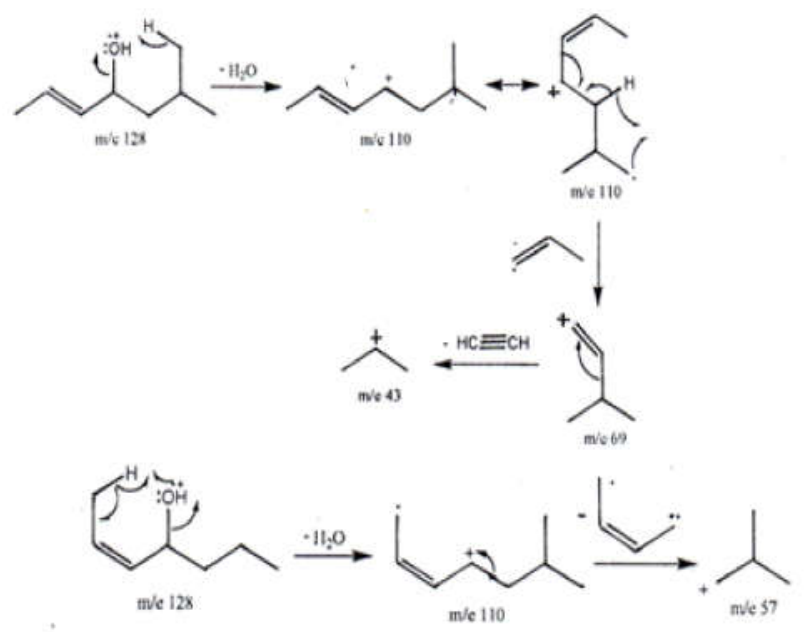

Gambar VIII. Pola fragmentasi 6-metil-2-hepten-4-ol, dehidrasi alkohol

Bukti lain yang memperkuat terbentuknya senyawa 6-metil-2-hepten-4-ol adalah adanya penembakan pada ikatan rangkap $\mathrm{C}=\mathrm{C}$ yang terjadi pada ion molekulernya. Adanya penembakan pada ikatan rangkap ini menimbulkan puncak dengan m/e 113 dan m/e 86. Pola fragmentasinya diagambarkan sebagai berikut :
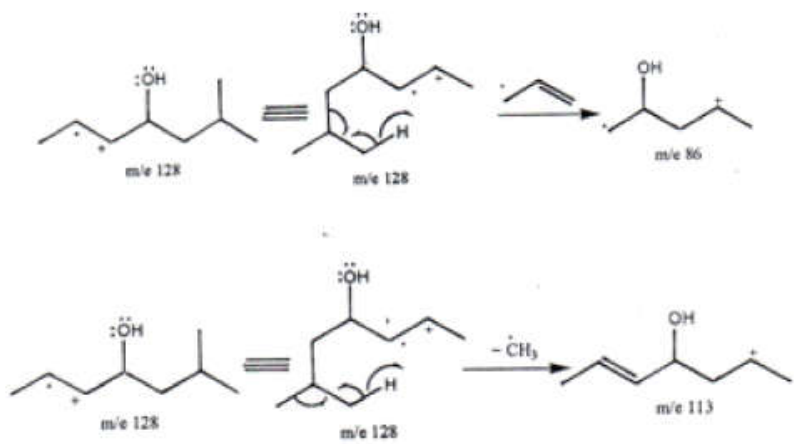

Gambar IX. Pola fragmentasi 6-metil-2-hepten-4-ol, pemecahan ikatan rangkap

\subsection{Analisa kuantitatif senyawa hasil sintesis 6-metil-2-hepten-4-ol}

Kromatogram gas hasil senyawa sintesis 6-metil2-hepten-4-ol ditampilkan dalam gambar berikut:

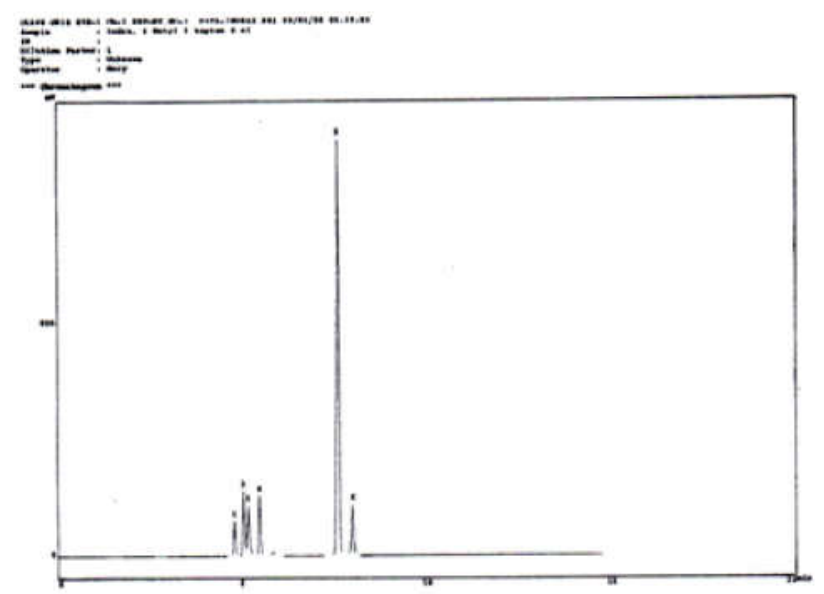

Gambar X. Kromatogram senyawa hasil sintesis 6-metil-2-hepten-4-ol
Berdasarkan gambar diatas diketahui bahwa senyawa hasil sintesis 6-metil-2-hepten-4-ol masih bercampur dengan senyawa-senyawa lain, yakni muncul 6 puncak masing-masing dengan $t_{R} 4,787$ menit; 5,036 menit; 5,163 menit; 5,467 menit; 7,601 menit dan 7,981 menit. Apabila kromatogram ini dibandingkan dengan kromatogram bahan dasar Nampak bahwa puncak dengan $t_{R}$ 7,601 menit merupakan puncak dari senyawa 6-metil2-hepten-4-ol dengan persen kemurnian sebesar 66,07 \%. Sedangkan puncak-puncak lain merupakan sisa dari bahan dasar dan impuritis bahan dasar.

Berdasarkan perhitungan persentase hasil diperoleh persen hasil sebesar 46,31\%. Nilai ini diperoleh dengan menetapkan bahan dasar krotonaldehid sebagai pereaksi pembatasnya. Faktor-faktor yang berperan penting dalam sintesis dengan reaksi Grignard ini antara lain kondisi reaksi pada waktu refluks yang jika kurang pelarut eter dapat menyebabkan terjadinya reaksi samping menghasilkan alkana dan pembentukan reagen Grignard yang kurang sempurna hal ini diketahui berdasarkan data kromatogram senyawa hasil sintesis 6-metil-2-hepten-4ol pada gambar III.10 menunjukkan masih adanya sisa isobutil bromida serta adanya krotonaldehid yang tidak terkonversi menjadi 6-metil-2-hepten-4-ol.

\section{KESIMPULAN DAN SARAN}

Senyawa 6-metil-2-hepten-4-ol dapat disintesis menggunakan reagen Grignard isobutilmagnesium bromida dan krotonaldehid. Senyawa hasil sintesis 6-metil2-hepten-4-ol melalui reaksi Grignard diperoleh persen kemurnian 66,07\% dan persen hasil 46,31\%.untuk mendapatkan persen kemurnian dan persen hasil yang lebih baik perlu disarankan pengontrolan pelarut eter pada proses refluks dan perlu dilakukan metode pemurnian terhadap senyawa hasil sintesis. Selain itu perlu dilakukan uji aktivitas terhadap feromon 6-metil-2-hepten-4-ol hasil sintesis untuk mengetahui seberapa besar tingkat ketertarikan kumbang Rhynchophorus spp sehingga dapat berfungsi sebagai pengendali hama kumbang kelapa secara efektif dan efisien.

\section{DAFTAR PUSTAKA}

[1] Ekasari, R., 2002, Karakterisasi Komponen Feromon Aggregat Kumbang Kelapa Jantan (Rhynchophorus schach), Universitas Brawijaya, Malang.

[2] Everett, T. S., 1998, The Grignard Reaction : Synthesis of a tertiary Alcohol, J. Chem. Educ., 75, 86-7.

[3] Gothama, A., and I.G.A.A. Indrayani, 1989, Potensi Tiga Nuklear Polyhedroses Virus untuk Pengendalian Helicoverpa Armigera Hubner (Lepidoptera: Noctuidae) pada Kapas, J. Lit. Pert Balit. Malang 2(4), 112-115.

[4] Roberts, R.M., Gilbert, J.C., Rodewald, L.B., and Wingrove, A.S.,1985, Modern Experimental Organic Chemistry, $4^{\text {th }}$ edition, CBS College Publishing, New York, pp 546-549.

[5] Suara Merdeka, Rabu, 22 Mei 2002, Puluhan Hektar Kelapa Terserang Wangwung, hal 1,2. 
[6] Warren, S., 1994, Sintesis Organik Pendekatan Diskoneksi, Penerjemah : Reksohadiprodjo, Gadjah Mada University Press, Yogyakarta, Hal 119-120.

[7] Zarbin,P.H.G., M. Yonashiro., and Perissini, 1998, An Alternative Route for the Synthesis of (E)- $(+)-5(\mathrm{~S})$ - Methylhept-2-en-4-one (Filbertone), J. Braz. Chem. Soc., 9(6):583-585. 